\title{
Enhancement of the Walbrzych Hard Coal Mines Geographic Information System for its application in studies of mining deformations
}

\author{
Jan Blachowski ${ }^{1, *}$, and Paulina Herkt ${ }^{1}$ \\ ${ }^{1}$ Wrocław University of Science and Technology, Faculty of Geoengineering, Mining and Geology, 27 Wyb. Wyspiańskiego St., \\ 50-370 Wrocław, Poland
}

\begin{abstract}
Geographic information systems (GIS) have been increasingly used in augmenting studies of mining and post-mining areas such as surface deformation analyses, risk assessment associated with old mining sites, identification of old mining sites and other. Up-to-date and complete geodatabase is an indispensable element of any geoinformation system facilitating such geospatial analyses. In this paper the process of verification and integration of Walbrzych Hard Coal Mines geodatabase and project of enhancing the Deformation Information System for these mines with web map application of underground workings and query tools developed with free and open source software (FOSS) have been described. The interactive map allows users to interact and obtain precise information on location and characteristics of underground mining and the query tools streamline pre-processing operations necessary for geospatial analyses.
\end{abstract}

\section{Introduction}

Geographic information systems (GIS) have been increasingly used in augmenting studies of mining and post-mining areas. The flexibility of GIS in handling and processing of large datasets, varied in terms of sources and formats, as well as GIS analytical capabilities have been used to solve problems associated for example with processing of satellite radar interferometry (InSAR) results for analysis of ground movements in areas of former underground hard coal mining [1-4], risk assessment associated with destruction of old underground workings and subsequent appearance of discontinuous deformations on surface [5-8], identification of abandoned underground mines [9, 10] and other issues.

In case of old and now abandoned underground mines development of GIS database with complete geometrical and attribute information on former mining activity in a given area requires additional work and attention. This is because, in many cases data sources, usually old paper mine plans or maps may be lost, incomplete or damaged and the digital coding of such documents is time consuming. Depending on the data available, needs and GIS skills of researchers, geoinformation systems used in studies of former mining sites differ in functionality, ranging from simple digital data repositories and visualization tasks to advanced systems with tools and functions for complicated analyses.

This paper presents the current status of development of the Deformation Information System for the underground hard coal mines in Walbrzych with special focus on development of interactive web map with free and open source software (FOSS) and query tools to facilitate preprocessing operations associated with surface deformation analyses.

\section{Geology and coal mining in the Walbrzych Coal Basin}

It is estimated that hard coal mining in Wałbrzych started in the 14th Century. At that time coal was mined from the surface. With the progress of time underground methods were introduced and coal production intensified. In the second half of the 19th Century mining of mineral from coal fields located under human settlements and infrastructure (roads, railways, etc.) began. After the World War II coal production peaked in 1955 with $3,25 \mathrm{M}$ tonnes, later on the values oscillated around 2,5M tonnes per year. Mining gradually ceased between 1993 and 1999. The steady drop in production of coal was accompanied by controlled flooding of underground workings through decrease in mining drainage of rock mass. The process of mine flooding was started in 1994 and because of favourable geological settings particular coal fields could have been flooded independently [11].

The Wałbrzych coal basin is of a limnic-type, that is deposition of material took place in intra-mountainous sedimentary basins. This has resulted in a mixed exogenous - endogenous coal deposit [12]. The geology of the basin is complicated in terms of deposit

\footnotetext{
* Corresponding author: jan.blachowski@pwr.edu.pl
} 


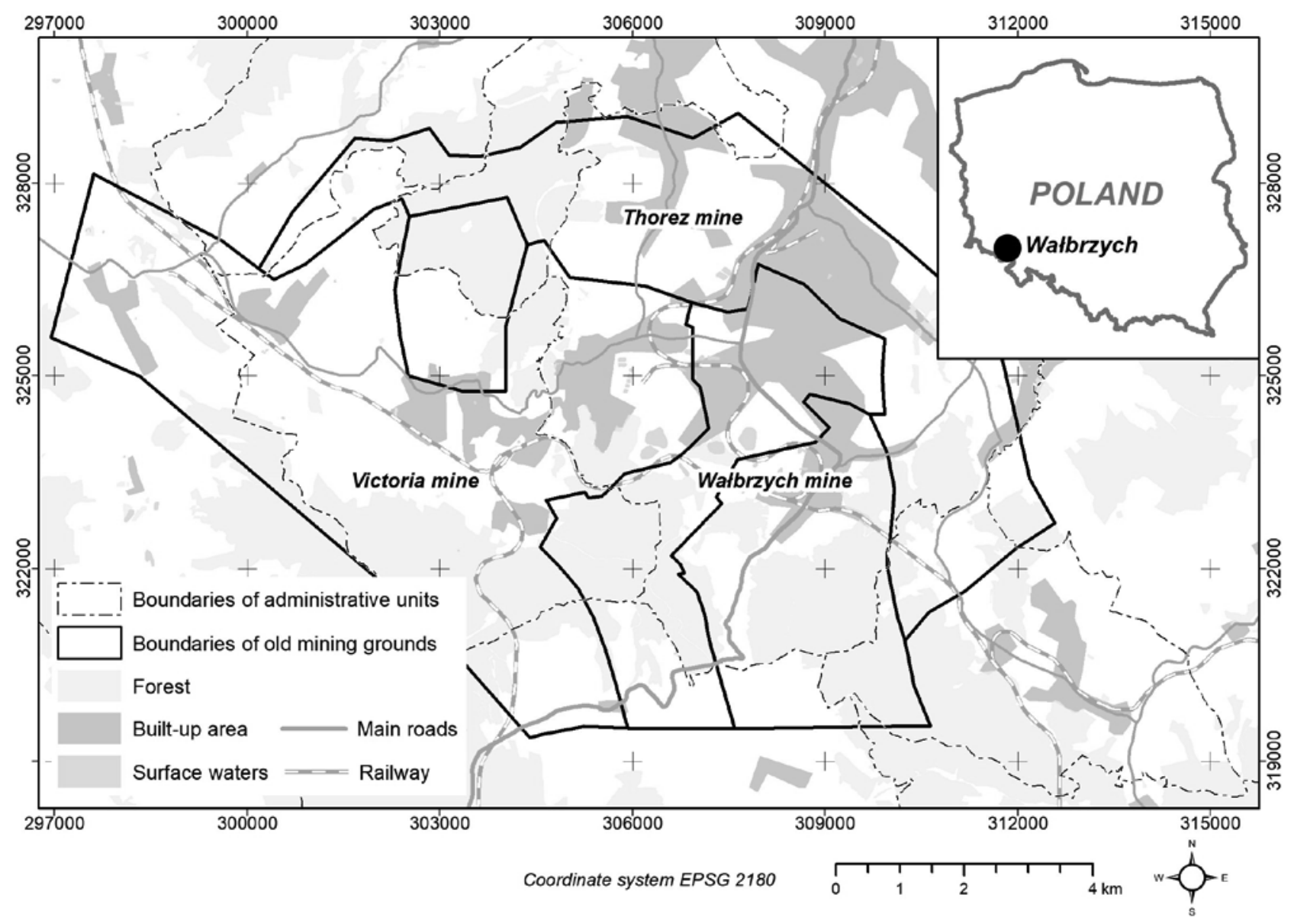

Fig. 1. Location of the old Hard Coal Mines in Walbrzych.

continuity, inclination, thickness and tectonic conditions [13]. The coal layers are associated with three of the four lithostratigraphic Pennsylvanian complexes, i.e.: Žaclér Biały Kamień and Wałbrzych formations. Altogether, 80 coal seams have been documented, including 48 in the Žaclér and 30 in the Wałbrzych formations. The coal layers are inclined in the direction of the centre of the basin, and the dip ranges from several to over 30 degrees, and even 60 degrees in the basin edges. Most of numerous faults trend from NW towards SE with the influence of the Chelmiec intrusion clearly marked by longitudinal and latitudinal faults. The throw of the main faults reaches $300 \mathrm{~m}$. In addition, there are numerous local faults in the coal-bearing layers, with throws of several metres [12].

Difficult mining conditions were the main reason for high costs of mining and closure of mines in Walbrzych. Location of the old coal basin has been shown in Fig. 1.

\section{Chronology of development of geoinformation system for the Walbrzych Hard Coal Mines}

This work is a continuation of studies started in the Wroclaw University of Science and Technology in 2006 and presented in papers by Blachowski [14], Blachowski and Stefaniak [15], Blachowski and Stefaniak [16] and Blachowski et al. [17]. The first one focused on development of a GIS database structure for storage and handling of numerical data related to underground mining of hard coal in the Walbrzych area. The results include a logical database structure and geodata describing coal mining for two of the three Walbrzych mines, i.e. the Thorez/Julia and the Victoria mines [14]. The succeeding work [15] produced geodata characterizing coal mining in the third mine Walbrzych and the remaining coal field Barbara in the Victoria mine. The study was also aimed at development of GIS procedures augmenting studies of ground deformation in the city of Walbrzych such as search and query tools according to selected criteria. The criteria being: depth of mining, mining method, coal panel thickness, coal panel inclination, and time of mining. This work was followed by a study on the application of self-organising maps (SOMs) to explore and analyse geodata describing factors associated with ground subsidence and study influence of particular ground subsidence factors on the observed surface subsidence, as well as the relationships between these factors [16]. It has been found that exploratory spatial data analysis is useful to identify relationships in multidimensional data related to mining induced ground subsidence.

These studies have resulted in a concept of a GIS based deformation information system for studies of ground movements on mining and post-mining grounds. The concept has been presented in a paper published in 2014 [17]. The proposed system's architecture 
developed for the Walbrzych mines consists of data collection, data visualization components, as well as spatial data mining, modelling and classification modules. The core of the system is a geodatabase storing vector and raster format data related to mining, geology, deformation surveying, landuse, etc. The analytical tools developed and implemented in the system include functions:

- to interpolate subsidence surfaces from discrete point measurements, assess quality and accuracy of interpolations and store them in raster format,

- to calculate basic parameters characterising ground deformation in space and in time such as: tilt, curvature, and horizontal strain,

- to classify area based on these parameters and in accordance with mining ground classification used in Poland, spatial regression functions to model and predict ground subsidence, and

- functions for data preprocessing for external applications.

The main purpose of the system is to facilitate and support studies of ground deformation during and after end of coal mining in the city of Walbrzych. The system's application have been presented in papers by Blachowski and Milczarek [18], and by Blachowski [19], as well as in doctoral dissertation by Milczarek [20]. The first one analysed surface changes in the Walbrzych mining grounds that occurred between 1886 and 2009. The analysis has been based on comparison of historical and present-day topographic maps and map algebra functions in GIS. The second, utilized spatial regression methods to determine relationship between subsidence (dependent variable) and subsidence factors (independent variables). The model has been then used o predict subsidence in areas that have not been surveyed. The last one used the system's geodatabase for construction of models for deformation calculations with finite element method (FEM).

In an associated study by Blachowski and Nowacka [21], an interactive web map application for presentation of information on remaining and now demolished buildings and shaft towers of one of the former mines Thorez has been developed.

In the following chapters, methodology and results of current work on database integration and web presentation of underground workings has been described. Verification of database completeness and integrity has been done within M.Sc. diploma thesis [22] at the Wroclaw University of Science and Technology.

\section{Verification and integration of geodata}

The main source of information on coal mining in the past comprised of mining maps and associated geological and mining documentations. Each coal layer has been mapped at various scales: 1:1 000, 1:2 000 and 1:5000 and each layer has been represented by sections. The number of sections ranged from few to several dozen for each coal layer depending on map scale. Overall, 29 coal levels have been digitised for the Victoria coal mine, 28 coal levels for the Walbrzych coal mine and 18 for the Julia/Thorez coal mine. In total several hundred map sections have been examined, georeferenced and digitised to a vector format with additional coding of attributes that describes mining. Fragment of an example map section with geometry and attribute information that could be interpreted has been shown in Fig. 2.

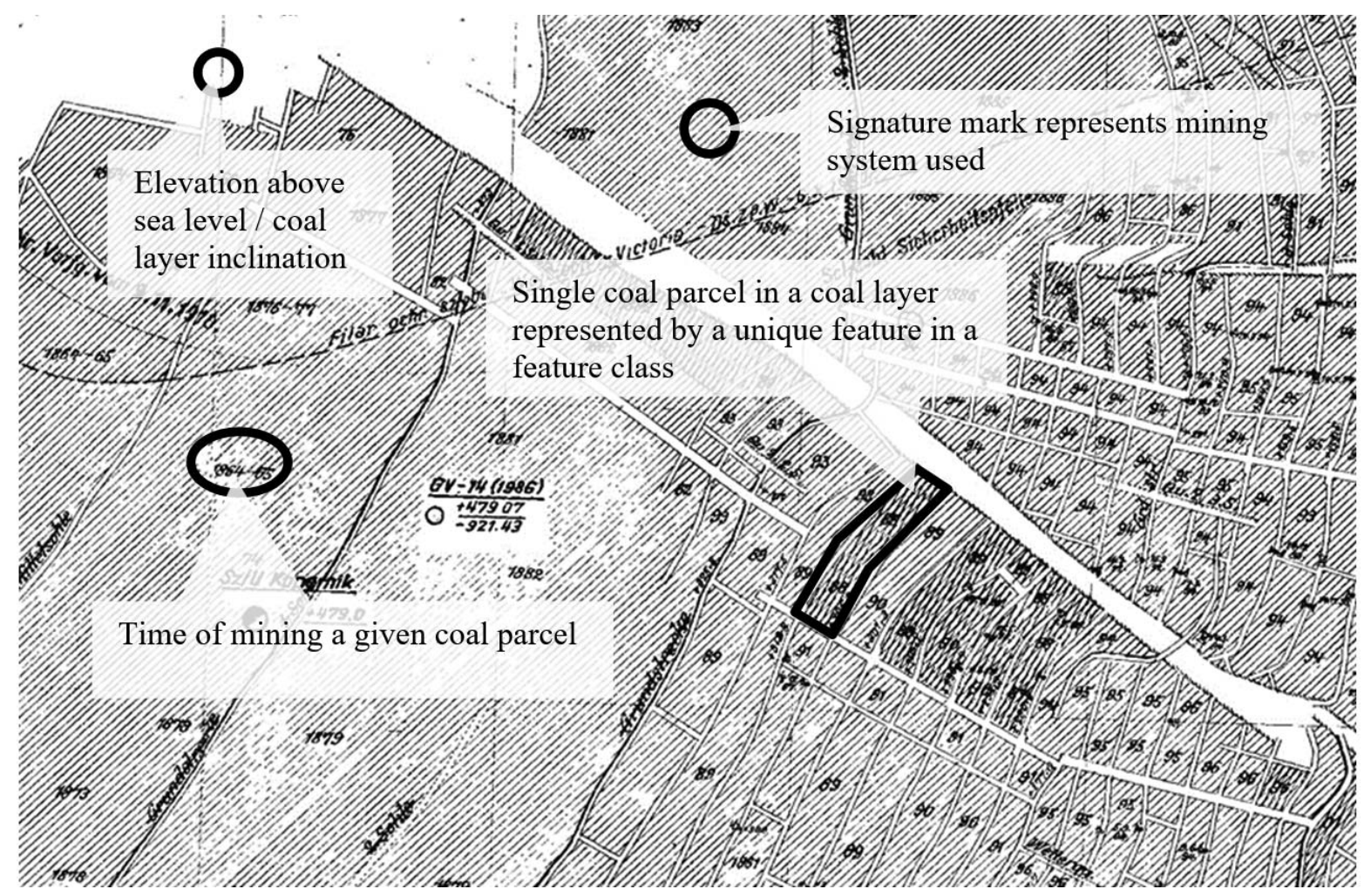

Fig. 2. Sample section of mine plan used for geodatabase development. 
Within the presented project the GIS data developed for each mine have been integrated in a common geodatabase. In this process field names of feature classes have been standardized, geometry and topology of features has been checked, as well as attributes checked for missing or wrong values. The final database structure comprises of polygon feature classes representing each a given coal layer with the following attribute information associated with each feature class object (coal parcel):

- Start time (of mining), date format,

- End time (of mining), date format,

- Mining system, string format,

- Mining system (code), string format,

- Coal layer thickness, number format,

- Coal parcel area, number format,

- Coal parcel volume, number format.

Other feature classes stored in geodatabase represent: location of mine shafts, location of main galleries and drifts, boundaries of mine shaft protection areas, boundaries of old mining grounds, as well as geodetic data representing surface deformations.

The next stage of the project focused on developing query tools to find and select coal parcels that meet given criteria. The search and query tools have been developed with Python language and implemented as a Python Toolbox in ArcGIS platform. Three query algorithms have been prepared, (1) query based on single parameter, (2) query based on a single parameter and a given range of values, and (3) query based on three parameters.

The first tool is a simple query returning features that meet a value provided, e.g. all parcels that were mined with a selected mining system.

In the case of (2) user can query the following criteria: time of mining (start and end time), thickness (minimum and maximum), as well as area and volume (minimum and maximum). In addition, two values that define the range are required, e.g. parcels mined from 1900 to 1910 .

The third tool is the most complex and allows to select features that meet three criteria, including two based on a range of values, e.g. features representing coal parcels mined with wall system with dry fill, thickness from $1.0 \mathrm{~m}$ to $1.5 \mathrm{~m}$ and extracted between 1900 and 1950.

Graphical user interface of tool with three parameters has been presented in Fig. 3.

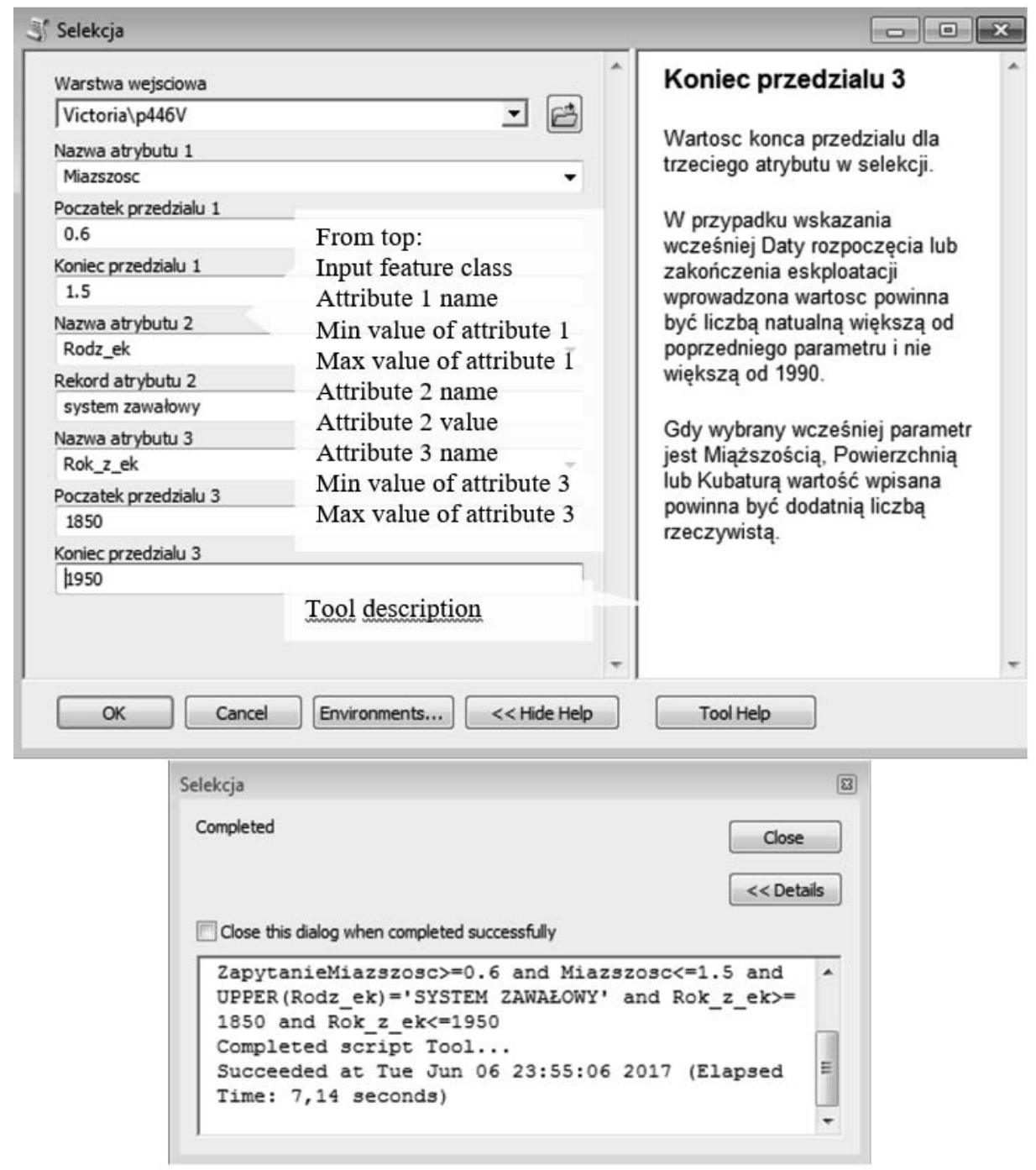

Fig. 3. Graphical user interface of representative tool (top) and result of its application (bottom) [22]. 


\section{Development of web map application}

In the development of test web map application for interactive visualisation of spatial and descriptive information on historical mining in Walbrzych open source QGIS (http://www.qgis.org/pl), Geoserver (http://geoserver.org) software distributed under the GNU General Public License have been used. Geospatial data representing particular coal fields and coal parcels in vector format have been stored in PostgreSQL database with PostGIS interface. To browse geospatial data provided by Geoserver the Geoexplorer application has been utilised. Implementation of the database required change of character encoding to UTF-8 from Windows-1250 code and change of attribute column names in data imported to new database for the three mines: Thorez/Julia, Victoria and Walbrzych. Then, the following scheme of naming thematic layers representing coal parcels have been used Mine_name_Mine_coal_layer_number. Configuration of the system included creation of workspace with warehouses storing particular thematic layers with assigned workspace, data source, host name and PostgreSQL database name, user name and password.

The last part of web map preparation concerned definition of Styled Layer Descriptor (SLD) file, which is a profile of the Web Map Service (WMS) standard containing user-defined symbolisation allowing for controlling the visual portrayal of geospatial data. In this step unique for each mining system used in Walbrzych mines signature marks have been defined in accordance with mine plans drawing rules. The proposed visualisation of thematic layers representing coal parcels according to mining system used has been presented in Fig. 4.

The GeoExplorer application has been configured with the following main functionalities: zooming in/out, panning, displaying layer properties, changing layer transparency, modifying layer style. In addition, the following tools have been implemented to support basic analyses in web map browser, i.e.: measurement tool, feature information in a pop-up window, attribute queries based on one or more criteria.

These functions have been shown in Fig. $5 \mathrm{a}$ and $5 \mathrm{~b}$ on the example of one coal layer in the Julia/Thorez mine. Fig. 5a shows pop-up window with formatted descriptive information associated with any given coal parcel. Mining system, time of working the given coal parcel (start and end time), thickness, as well as area and cubature are provided for user. In the same figure result of using the measure tool on a given coal parcel has been shown. Whereas, Fig. 5b presents outcome of an attribute query with results shown in the form of database records meeting the given criterion returned in a separate table window. In addition, the web map application allows to view location of coal layers against a given base map as a registered WMS service, for example present day land development shown on orthomosaic.

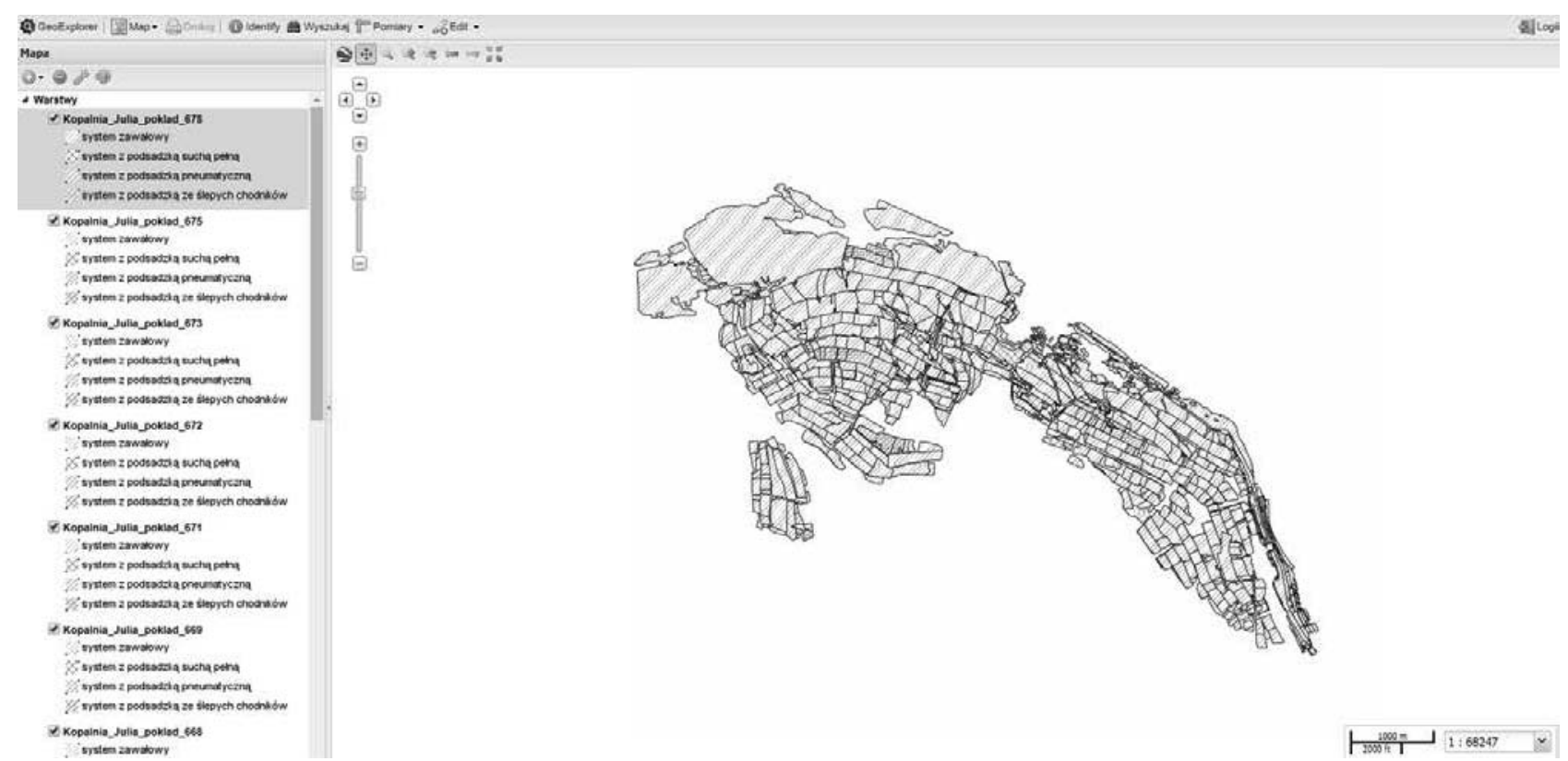

Fig. 4. Location of productive coal layers in the Thorez/Julia mine symbolised according to mining system used presented in open source web map application [22]. 


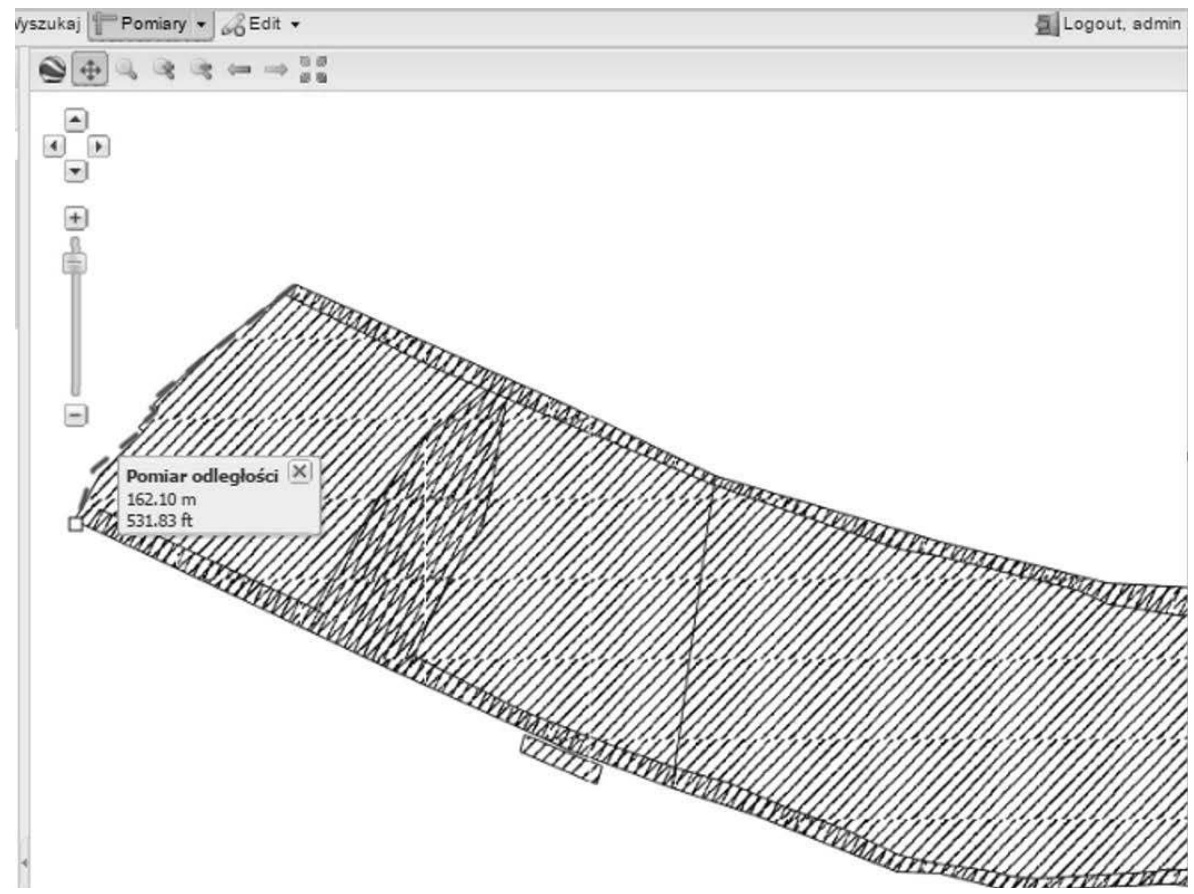

Fig. 5a. Example application of measure and feature information tools.

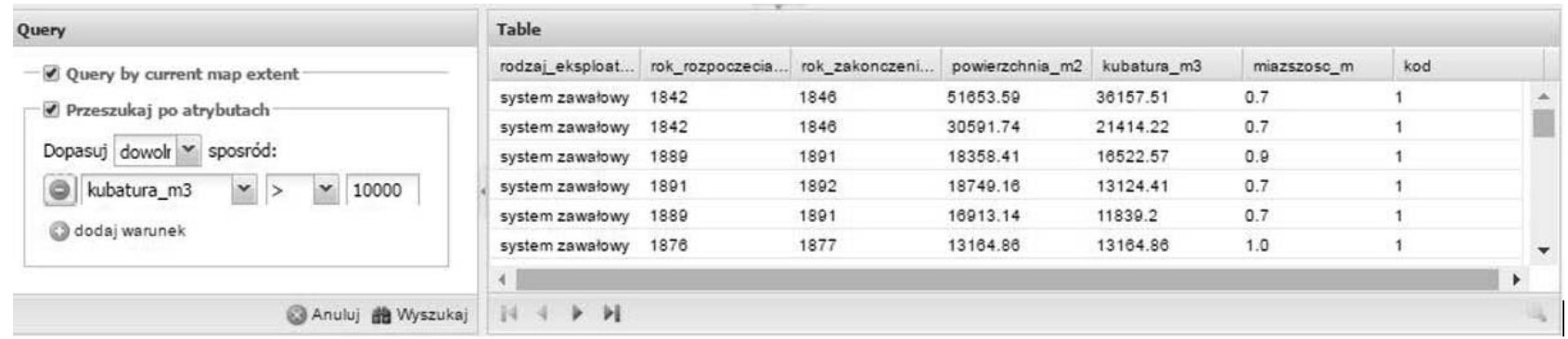

Fig. 5b. Example application of query functionality.

\section{Discussion and conclusions}

The paper presented universal methodology for development of a GIS and spatial analysis functions assisting studies of underground coal mining on its surroundings. Digitising available data on former mining activity helps to preserve this information for research purposes, e.g. location of former mining sites in the field, as well as create visualisations for dissemination to broader public. An important aspects of such initiatives is the ability to construct complete, in terms of space and time database. This process is sometimes obstructed by incomplete, damaged or even lost data.

Integration of geospatial data representing three adjacent underground hard coal mines in a geodatabase in the presented case, facilitates joint and comprehensive spatial analyses of coal mining and its effects on surface for the entire area of Walbrzych.

With the aim to streamline pre-processing operations necessary for geospatial analyses three query tools have been developed with Python language scripting. These have been used for example in spatial regression analyses connecting deformation factors with the changes observed on the surface (ground movements) [19].

The web map application prepared with open source tools shows how to effectively disseminate geospatial information for a wider audience in an easily accessible way. Web map users can use simple query and spatial analysis tools provided with the application and obtain precise information on location and characteristics of underground mining interesting for local communities such as congruence of coal fields and present day land development.

This work was partly financed from statutory grant no 0401/0123/2017 at the Faculty of Geoengineering, Mining and Geology, Wroclaw University of Science and Technology.

\section{References}

1. M. Caro Cuenca, A.J. Hooper, R.F. Hanssen, Journal of Applied Geophysics, 88 (2013)

2. S. Samsonov, N. d'Oreye, B. Smets., International Journal of Applied Earth Observation and Geoinformation, 23 (2013) 
3. A. Sowter, L. Bateson, P. Strange, K. Ambrose, M. Fifik Syafiudin, Remote Sensing Letters, 4:10 (2013)

4. L. Bateson, F. Cigna, D. Boon, A. Sowter, International Journal of Applied Earth Observation and Geoinformation, 34 (2015)

5. T. Esaki, I. Djamaluddin, Y. Mitani, Q. J. Eng. Geol. Hydroge., 41 (2008)

6. F. Mancini, F. Stecchi, G. Gabbianelli, Eng. Geol., 109 (2009)

7. K.D. Kim, S. Lee, H.J. Oh, Environ. Geol., 58 (2009)

8. I. Park, J. Lee, L. Saro, Central European Journal of Geosciences, 2 (2014)

9. S. Mei, V. Poncos, C. Froese, EUB/AGS Earth Science Report (2007)

10. M. Mathey, Proceedings of the 13th ISM Congress (2013)

11. J. Fiszer, A. Gogolewska, Changes of groundwater conditions during the process of Lower Silesian Coal Basin closure (Wroclaw University of Technology, Institute of Mining Engineering Report No. 35, 2003, in Polish)

12. K. Kominowski, Geology and hydrogeology, [In:] A. Kowalski (Ed.) Mining and surface protection. Experiences from the Walbrzych mines (Central Mining Institute, Katowice, 2000, in Polish)

13. S. Kożuchowicz, J. Oprychał, Geological documentation of coal deposits in the Walbrzych Hard Coal Mine Walbrzych (Przedsiębiorstwo Geologiczne, Wrocław, 1984, in Polish)

14. J. Blachowski, Mining Science, X:1 (2008, in Polish)

15. J. Blachowski, P. Stefaniak, Mining Science, 135(42) (2012, in Polish)

16. J. Blachowski, P. Stefaniak, Mining Science, 20 (2013)

17. J. Blachowski, W. Milczarek, P. Stefaniak, Nat. Hazards Earth Syst. Sci., 14 (2014)

18. J. Blachowski, W. Milczarek, Geological Quarterly, 58:2 (2014)

19. J. Blachowski, Natural Hazards, 84 (2016)

20. W. Milczarek, Analysis of ground surface changes after mining exploitation in the chosen region of the former Walbrzych basin (Ph.D. thesis, Wroclaw University of Technology, Poland, 2011, in Polish)

21. J. Blachowski, A. Nowacka, Mining Science, 133(40) (2011)

22. P. Herkt, Development of integrated geoinformation system of abandoned underground coal mines in Watbrzych (Master thesis, Wroclaw University of Science and Technology, Poland, 2017) 